\title{
Incorporating Diversity and Inclusion in the Computing Classroom
}

\section{Dr. Bridget Benson, California Polytechnic State University, San Luis Obispo}

Bridget Benson received a Bachelor's degree in Computer Engineering at California Polytechnic State University San Luis Obipso in 2005, a Master's degree in Electrical and Computer Engineering at the University of California Santa Barbara in 2007 and a $\mathrm{PhD}$ degree in the Computer Science and Engineering at the University of California San Diego in 2010. She is currently an Associate Professor in the Electrical Engineering Department at California Polytechnic State University San Luis Obipso. Her research interests span engineering education, embedded systems, and ecological monitoring.

\section{Joseph Callenes, Cal Poly San Luis Obispo}

Joseph Callenes received his $\mathrm{PhD}$ in Electrical and Computer Engineering from the University of Illinois at Urbana-Champaign, and is currently an Assistant Professor of Electrical and Computer Engineering at California Polytechnic State University in San Luis Obispo.

\section{Dr. Amin Malekmohammadi, California Polytechnic State University, San Luis Obispo}

Professor Malek Mohammadi is a fellow of the UK Higher Education Academy (FHEA) and a Senior Member of IEEE, Member of Engineering Council (CEng), IET and Optical Society of America (OSA) and has published over 90 Scientific Research Papers and a Postgraduate Textbook. Currently, he has two successful commercialized products and is the holder of 4 patents on Telecommunications Systems. 


\title{
Incorporating Diversity and Inclusion in the Computing Classroom
}

\author{
Bridget Benson, Joseph Callenes-Sloan, Amin Malekmohammadi \\ Electrical Engineering Department, Cal Poly State University San Luis Obispo
}

\section{Introduction}

The need for a diverse and inclusive workplace is becoming well-recognized by the Tech industry. The Forbes Technology Council identified 12 ways diversity makes a difference in Tech including increased creativity, better product solutions, increased ability to connect with customers, and even increased profits [1]. However, men still hold $76 \%$ of technical jobs and those who identify as African American or Latinx make up only 5\% of the technical workforce [2]. Women and under-represented minorities often experience racism and/or sexism within the computing field thus contributing to the non-inclusive (and as a result less diverse) educational or industrial workplace [3].

Many tech companies have created programs and initiatives to promote diversity and inclusion in computing fields including hiring Chief Diversity Officers and changing hiring practices. However, these programs have had varying levels of success [4]. One company that has had particular success in the realm of diversity and inclusion, Slack, has had success not because they've hired a Chief Diversity Officer (they haven't), but because they embed diversity and inclusion awareness into their everyday processes [5].

The National Science Foundation and many Colleges and Universities have also made a commitment to increasing diversity and inclusion [6-7]. And like Slack, they've noticed that real change can occur when diversity and inclusion become part of the everyday activities of the institution. So how can individual faculty members bring diversity and inclusion activities into their everyday classrooms?

Guidelines exist on how to create inclusive college classrooms [8-10], however, faculty may be overwhelmed by the plethora of suggestions and fail to see how to concretely implement these suggestions within the context of their specific course. Also, some faculty, particularly in STEM disciplines, may find it hard to address diversity and inclusivity concepts in an education environment where only technical content is traditionally taught. Students may find it obvious to talk about diversity and inclusion in a social justice course, but may find discussing these issues to be out of place in a computing course.

This paper looks at concrete ways to implement two proven diversity and inclusion activities into a computing course. These activities involve getting students to know one another and exposing students to successful role models from diverse backgrounds. Decades of research shows how valuable getting people to know one another is for reducing discrimination and enhancing 
diversity [11-12]. Seeing successful role models in a particular field who are similar to themselves helps students build confidence that they too can be successful in that domain [1316]. Though the techniques described in this paper can be applied to any course, we provide examples on how we implemented them specifically in a lower-division undergraduate computer design course so that computing instructors can see how these activities can be made relevant in their domain. It is our hope that this paper will give computing faculty (and faculty in general) concrete ideas on how to successfully (and somewhat easily) promote diversity and inclusion within their classrooms.

The rest of this paper is organized as follows: Methods discusses the specific diversity and inclusion activities we implemented in our computing classroom. Assessment describes the survey instrument (and its results) that we used to examine how our efforts affected students' perceptions of the need for diversity in the field of computing as well as the student's feelings of inclusion within the computing classroom. We conclude with a Discussion on the successes and short-comings of our activities.

\section{Methods}

In this section we discuss how we specifically implemented two proven diversity and inclusion activities (Getting Students to Know One Another and Exposing Students to Successful Role Models From Diverse Backgrounds) into a lower division computer design course. This course is a studio course (where lecture and lab are combined in one course setting) that meets for 110 minute time blocks, 3 times per week, for 10 weeks. The course leads students through designing a 32-bit RISC-V processor in SystemVerilog (a hardware description language) and teaches students how to write assembly and $\mathrm{C}$ code to run on their processors. We implemented the diversity and inclusion activities in two sections of the same course (one section had 25 students while the other had 30 students) taught by the same instructor.

\section{Getting Students to Know One Another}

There exist many 'ice-breaker' techniques that can help students get to know one another [17]. The technique we decided to use included weekly seat rotations (so that students would sit next to different people each week) and daily ice breaker questions (so students could get to know something about each other each day).

Our seat rotations followed a solution to the social-golfer problem - a problem whose task is to schedule $\mathrm{g}$ x $\mathrm{p}$ golfers in $\mathrm{g}$ groups of $\mathrm{p}$ players for $\mathrm{w}$ weeks such that no two golfers play in the same group more than once. In other words, a solution to the social golfer problem ensures the quickest way for everyone to meet everyone else in the course when put into small rotating groups. You can find solutions to this problem for different values of ' $g$ ' and ' $p$ ' using Wolfram's tool [18]. 
For example, for the class of 25 students we used a solution for 7 groups ( $\mathrm{g}=7$ ) with 4 golfers per group $(\mathrm{p}=4)$ to come up with a weekly groupings (Figure 1). On the first day of class, we assigned each student a unique upper case or lower case letter in accordance with the social golfer solution. On the first day of each week, we wrote a seating chart on the white board (Figure 2) that followed the groupings prescribed by the social golfer problem while ensuring that students who requested to sit in the front (due to visual, auditory, or learning disabilities) would always have their group for that week sit in the front.

\begin{tabular}{|lccccccc|}
\hline Week1: & ABCD & EFGH & IJKL & MNab & Cdef & Jhij & klmn \\
Week2: & AEgk & BFMc & Ndhl & Glem & HJai & CKbn & DLfj \\
Week3: & AFjn & BEae & bfim & HKcl & GLMh & CINk & DJdg \\
Week4: & Alci & BJNn & EKMj & FLdm & begl & CGaf & DHhk \\
Week5: & AGbd & BHgm & ELNi & achn & FKfk & CJej & DIMl \\
Week6: & AKeh & BLbk & Flag & EJfl & Ncjm & CHMd & DGin \\
Week7: & AHNf & BGjl & FJbh & Meik & Eldn & CLcg & DKam \\
Week8: & ALal & BKdi & GJck & Mfgn & Hlbj & CEhm & DFNe \\
Week9: & AJMm & Blfh & CFil & DEbc & GKNg & HLen & Adjk \\
& & & & & & & \\
\hline
\end{tabular}

Figure 1: Solution to social golfer problem for 28 golfers in groups of 4 .

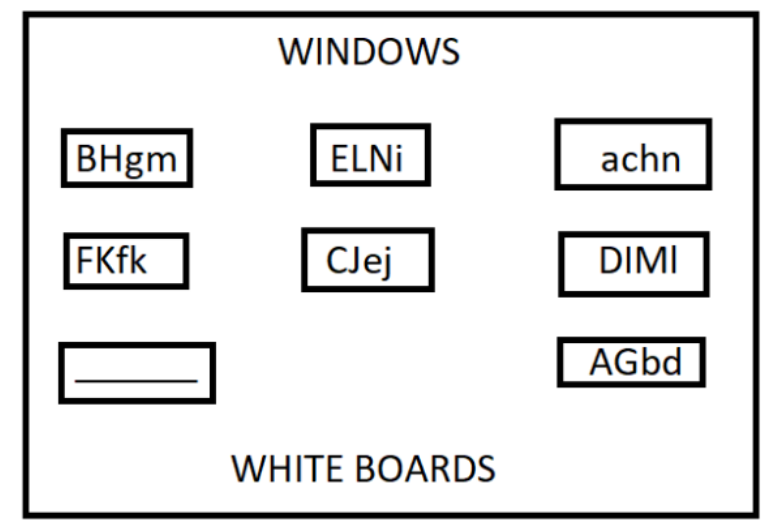

Figure 2: Example seating chart for Week 5 from Figure 1 with 4 students per bench.

We then spent the first 3 minutes of each class period having the students in their group of four learn (or re-learn) their groupmates' names and hometown as well as answer a daily ice-breaker question (such as what is your favorite sandwich shop in the area? Do you have any pets and if so what are they (or if not - did you ever want any)? [19] So by the end of the week, the students would hopefully know something about 3 other students in their class. By the end of 9 weeks, the students would have met every other student in the course. 


\section{Exposing Students to Successful Role Models From Diverse Backgrounds}

We took two approaches to expose students to successful role models from diverse backgrounds within the field of computing. The first approach was to highlight one computing contributor from an under-represented background each week by:

1. Placing a picture of that person on the learning management system's (LMS) weekly module (Example shown in Figure 3)

2. Providing students with a short lecture about the person and how their contributions fit into the history of computing and into the specific topics we were studying that week (see Table 1)

3. Sharing a short video (with close captions enabled) describing the life and/or contributions of that person in class (and providing a link to the video on the LMS) (Example shown in Figure 3)

\section{Week 1}

Course Introduction, Vivado Tool Flow \& systemVerilog Review, Memory

Computing Contributor of the Week - Ada Lovelace

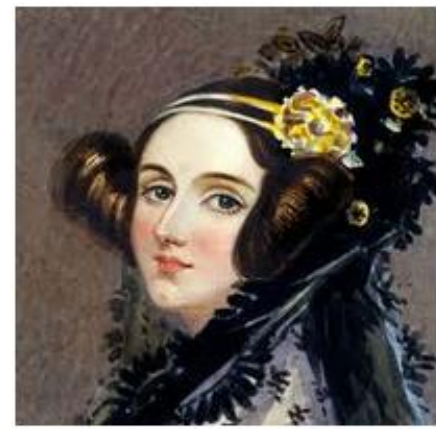

Ada Lovelace - a brief biography.

Lecture Resources

\section{Lec1-Muxes, Registers. Structural Modeling}

Lec2-Sim Files + Memory

Memory Lecture (Part 1 only)

Lecture Video (Part 1) : Memory, Interfaces, Memory Map

ProblemSet1

Lab Resources

Assignments: HW1

Figure 3: Week 1 Module from the course's LMS highlighting the computing contributor of the week 
Highlighting a computing contributor each week took about 10 minutes of class time. Table 1 shows the specific computing contributors we selected each week along with their known underrepresented identity, their years of life, one of their major contributions to computing, and their relevance to that week's course work. As you can see, we generally followed a chronological order (to also tie in the contributor's work to the history of computing) and attempted to represent contributors from a wide variety of backgrounds. Because the last two weeks of the course were devoted to final projects (with no lecture period), we did not present any computing contributors during this time. Because of the limited number of contributors that we could present in the given time frame (8), we chose not to highlight a contributor without a known under-represented identity because the focus of this effort was to highlight contributors from under-represented identities. However, in the written assignment (described below) we allowed students to write about contributors from any background (both under-represented and overrepresented) to be sure to not exclude any identities.

Table 1: Selected Computing Contributors from Diverse Backgrounds

\begin{tabular}{|l|l|l|l|l|l|}
\hline Week & $\begin{array}{l}\text { Contributor } \\
\text { Name }\end{array}$ & $\begin{array}{l}\text { Known Under- } \\
\text { represented } \\
\text { identity(ies) }\end{array}$ & $\begin{array}{l}\text { Years } \\
\text { of Life }\end{array}$ & Major Contribution & $\begin{array}{l}\text { Relevance to } \\
\text { Coursework }\end{array}$ \\
\hline 1 & Ada Lovelace & Female & $\begin{array}{l}1815- \\
1852\end{array}$ & $\begin{array}{l}\text { One of the first computer } \\
\text { programmers }\end{array}$ & $\begin{array}{l}\text { Origins of } \\
\text { computing }\end{array}$ \\
\hline 2 & Grace Hopper & Female & $1906-$ & $\begin{array}{l}\text { Developed one of first } \\
\text { compilers }\end{array}$ & $\begin{array}{l}\text { Levels of } \\
\text { abstraction from } \\
\text { hardware to } \\
\text { software }\end{array}$ \\
\hline 3 & Alan Turing & Homosexual & $1912-$ & $\begin{array}{l}\text { Devised the concept of a } \\
\text { Turing Machine }\end{array}$ & $\begin{array}{l}\text { Instruction Set } \\
\text { Architecture }\end{array}$ \\
\hline 4 & $\begin{array}{l}\text { Katherine } \\
\text { Johnson }\end{array}$ & $\begin{array}{l}\text { Female, African } \\
\text { American }\end{array}$ & 1954 & $\begin{array}{l}\text { Calculated and verified } \\
\text { computer calculations for } \\
\text { space flight trajectories }\end{array}$ & $\begin{array}{l}\text { Testing and } \\
\text { Verification }\end{array}$ \\
\hline 5 & Dado Banatao & Filipino & $1946-$ & $\begin{array}{l}\text { First system logic chip set } \\
\text { and first Windows } \\
\text { Graphics accelerator chip }\end{array}$ & $\begin{array}{l}\text { Connecting a } \\
\text { computer to } \\
\text { peripherals }\end{array}$ \\
\hline 6 & Mark Dean & $\begin{array}{l}\text { African } \\
\text { American }\end{array}$ & $1957-$ & $\begin{array}{l}\text { Co-creator of first 1GHz } \\
\text { chip }\end{array}$ & $\begin{array}{l}\text { Enhancing the } \\
\text { RISC-V }\end{array}$ \\
\hline 7 & $\begin{array}{l}\text { Miguel de } \\
\text { Icaza }\end{array}$ & Hispanic & $1972-$ & $\begin{array}{l}\text { Started GNOME, Mono, } \\
\text { Xamarin projects }\end{array}$ & $\begin{array}{l}\text { C coding in Linux } \\
\text { for the RISCV }\end{array}$ \\
\hline 8 & $\begin{array}{l}\text { Christopher } \\
\text { Pauley }\end{array}$ & Autistic & $1991-$ & $\begin{array}{l}\text { Highlights importance of } \\
\text { Microsoft's Autistic } \\
\text { Hiring Program }\end{array}$ & $\begin{array}{l}\text { Importance of } \\
\text { Incorporating } \\
\text { diverse } \\
\text { perspectives into } \\
\text { project designs }\end{array}$ \\
\hline
\end{tabular}


Our second approach to exposing students to successful role models from diverse backgrounds within the field of computing was to give the students a short written computing contributor assignment. Figure 4 shows the assignment prompt.

We gave the assignment to the students during the 8th week of class (after we had completed presenting computing contributors) and asked for it to be completed by the last day of class during week 10 .

This assignment asks you to research (and/or interview) someone from an under-represented background who is making contributions to computing or someone from a well-represented background who is actively supporting diversity and inclusion in the computing workplace. You should choose a person whom you can relate to in some way (shares some aspect of your identity, has had similar life experience, shares similar goals, or simply inspires you, etc.). The person could be someone you know or someone you learn about from a book/internet/other people.

Write a short essay ( $\sim 3$ paragraphs) about the person that includes the following information:

1. A picture of the person

2. A brief biography of this person

3. The technical contributions of this person to the field of computing and/or the diversity/inclusion contributions of this person to the field of computing

4. Any 'trials and tribulations' this person faced and how they persevered through these challenges to succeed in what they did.

5. The reason you chose this person

The assignment will receive full credit if it is complete (meets the above requirements) and turned in on time.

Figure 4: Written Computing Contributor Assignment Prompt

\section{Assessment}

In order to assess if our efforts affected students' perceptions of the need for diversity in the field of computing as well as the student's feelings of inclusion within the computing classroom, we designed an Institution Review Board (IRB) approved anonymous survey consisting of Likert scale and open ended questions about our diversity and inclusion activities. We posted a link to this survey on the course's LMS and gave students multiple verbal and email reminders asking them to voluntarily complete the survey. As this was an IRB approved survey, answering any question was optional. Also, to keep the survey anonymous, we did not ask students to identify their specific gender, race, or ethnic background as this information could single out a specific student. Instead, we asked the following demographic questions:

1. Are (were) you a transfer student?

2. Are you a first generation student (first in your family to attend college)?

3. How many years have you been at **host institution** including this year? 
4. Do you consider your racial or ethnic group to be under-represented in the field of computing? (answer choices: Yes, No, Not sure)

5. Do you consider your gender to be under-represented in the field of computing? (answer choices: Yes, No, Not sure)

6. Do you consider other aspects of your identity to be under-represented in the field of computing? (answer choices: Yes, No, Not sure)

Of the 55 students surveyed, 10 responded (18\% response rate) and all of them answered every non-open ended question (only a few answered the open ended questions). Of the respondents, none of them were transfer students, none of them were first generation students, none of them considered their racial or ethnic group to be under-represented, $30 \%$ considered their gender to be under-represented and $20 \%$ considered other aspects of their identity to be under-represented. Their average year in school was 2.4 years.

Figure 5 shows the Likert scale questions and the average Likert Score (where $5=$ Strongly Agree, 4 = Agree, 3=Neutral, 2=Disagree, 1= Strongly Disagree) for the questions used to assess the effectiveness of the seat rotation and ice breaker activity. We also asked students the open ended question: "Do you have any suggestions on how the instructor can better help students feel included in the classroom?"

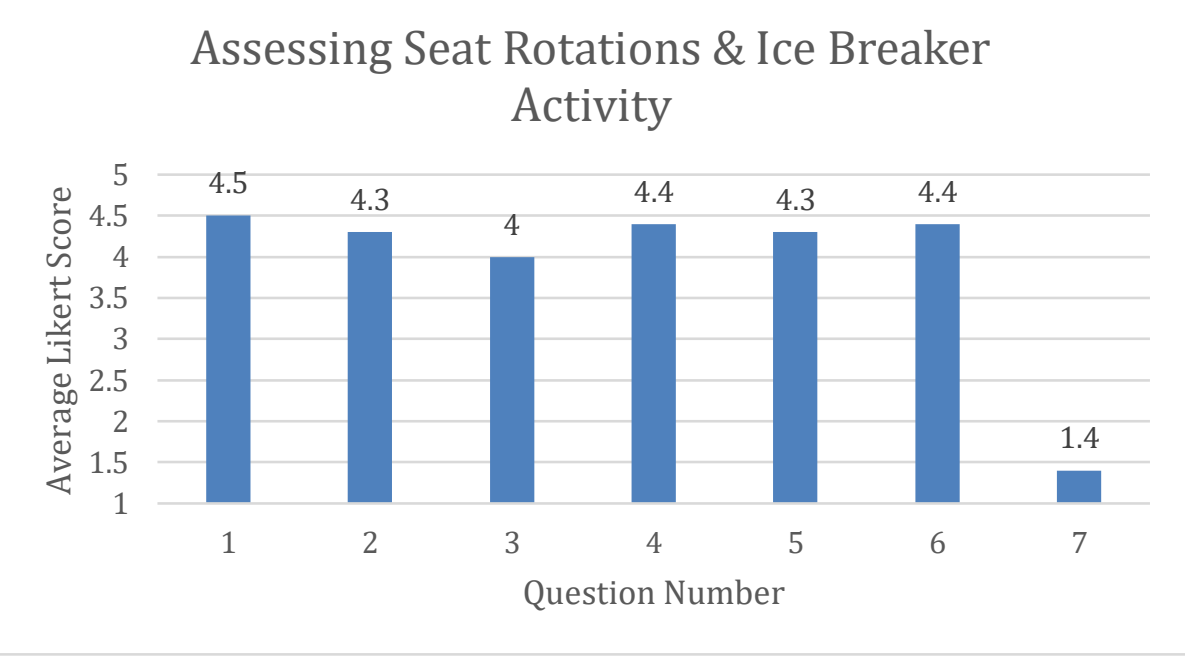

1. I got to know other students in the course

2. The weekly seating assignments helped me get to know more people in the class

3. I liked the weekly seating assignments

4. The daily ice breakers helped me get to know other students in the class

5. I liked the daily ice breakers

6. Getting to know other students in my class helps me feel more included in the classroom

7. I felt like I didn't belong in this class

Figure 5: Assessment for Seat Rotations \& Ice Breaker Activity 
From the responses, we see an overwhelming positive reaction to the seat rotation and ice breaker activity. Only one person disagreed with questions number 2 (The weekly seating assignments helped me get to know more people in the class) and 3 (I liked the weekly seating assignments). This student wrote:

"It is really hard to help women feel comfortable in such a male-heavy class. For the first week, I felt very comfortable as I was next to another woman whom I am friends with. After that, the seating was okay but I usually only felt comfortable by the last day of the seating. It was nice to sit next to many different people, but I would have felt the most comfortable had I been next to a previous friend. However, I felt that the ice breakers were helpful in starting a conversation with my male peers which can be a difficult task."

Only one person agreed with question 7 (I felt like I didn't belong in this class), although this same person still enjoyed the seat rotation and ice breaker activities.

To the open ended question, one student wrote:

"I would like to have more collaboration on weekly lab assignments."

Figure 6 shows the Likert scale questions and the average Likert Score (where $5=$ Strongly Agree, $4=$ Agree, $3=$ Neutral $/$ No change from how I felt before this course, 2=Disagree, $1=$ Strongly Disagree) for the questions used to assess the effectiveness of the weekly computing contributor activity. We also asked students the open ended question: "Were there other contributors you would have preferred to learn about than the weekly contributors that were presented? If so, who (and/or from what identity group)?"

From the responses, we again see a positive reaction to the weekly computing contributor activity - especially in its ability to help students better appreciate diversity in the field of computing (question 3). Only 1 person felt this activity was a waste of time and would not like other classes to do this activity. This person also identified as having a gender that is underrepresented in the field of computing. Only one person wished to spend more time on this activity (question 6) and specifically stated:

"I liked learning what people did with their careers because I have no clue what to do with mine. It gives me ideas! And hope!"

Only two students specifically answered the open ended question each stating:

"I thought the choice of contributors was good." 


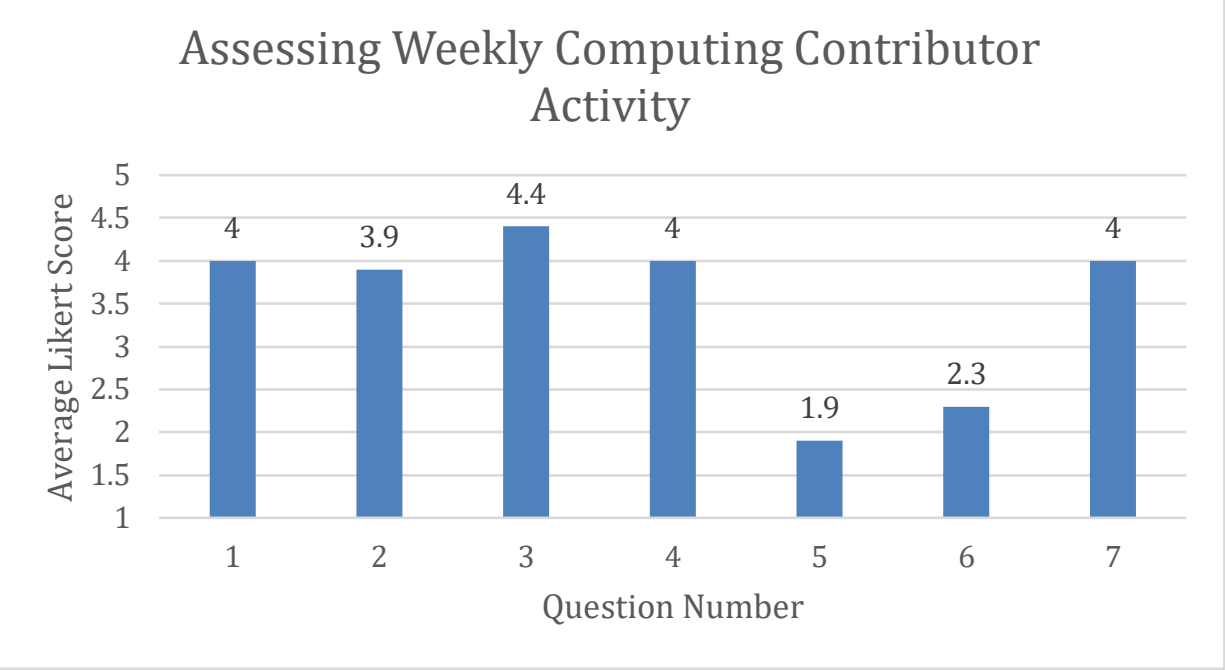

1. Learning about diverse contributors to computing helped me feel like I belong in the field of computing

2. Learning about diverse contributors to computing helped me feel more confident in my choice of major

3. Learning about diverse contributors to computing helped me better appreciate diversity in the field of computing

4. Learning about diverse contributors to computing is a useful activity for a computer design course

5. Learning about diverse contributors to computing was a waste of time in an already time consuming technical course

6. I would have liked to have more lecture time to learn about more contributors to computing

7. More Electrical and Computer Engineering courses should highlight diverse contributors to the field

Figure 6: Assessment for Weekly Computing Contributor Activity

Figure 7 shows the Likert scale questions and the average Likert Score (where $5=$ Strongly Agree, 4 = Agree, 3=Neutral / No change from how I felt before this course, 2=Disagree, 1= Strongly Disagree) for the questions used to assess the effectiveness of the written computing contributor assignment. We also asked students the open ended questions: "In general, how useful were the diversity and inclusivity activities for you. Feel free to talk about one, two, or all of the activities." And "How could the diversity and inclusivity activities be improved in the future? Are there other activities you would have liked to have seen?" 


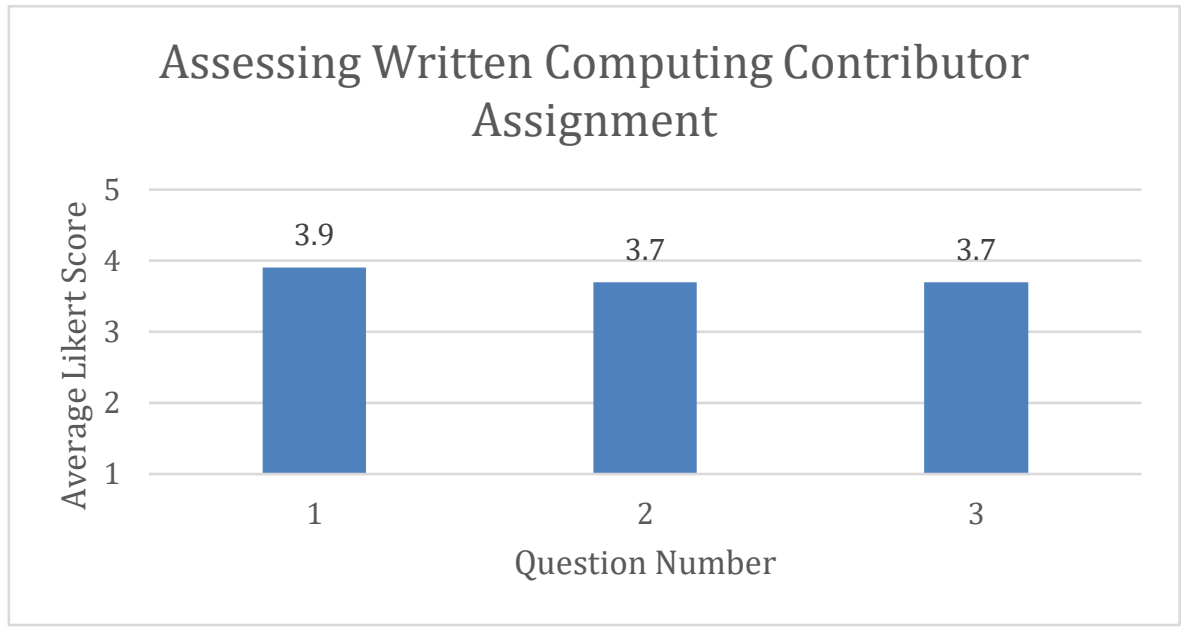

1. I enjoyed the computing contributor essay assignment

2. The computing contributor I studied inspires me

3. The computing contributor essay helped me better appreciate the need for diversity in the field of computing

Figure 7: Assessment for Written Computing Contributor Assignment

From the responses, we again see a positive reaction to the written computing contributor assignment. Only one person strongly disagreed with all three statements (the same person who did not enjoy the weekly computing contributors activity) and only one person disagreed with question 2 (the computing contributor I studied inspires me).

To the open ended question about the activities in general, students wrote:

"I really enjoyed this class. I think talking to new people is important. Sometimes it's a little out of my comfort zone but since everyone was pretty accepting of it, it was easy to talk to new people. I loved the computing contributors. Even though our final assignment was to write an essay, I actually really enjoyed learning about the person I chose and writing about her. It was really inspiring!"

"The activities helped me feel more included in the classroom, like I better understood my classmates."

"The activities changed my outlook and approach to things for the future. I felt like the icebreakers were effective communication activities. I was surprised how effective the final project presentations were to begin discussions with new people",

To the open ended question about other activities students would have liked to have seen, students wrote: 
"I would like to see something about how to personally help with the gender and diversity gap in computing. A presentation on individual actions to recognize and promote diversity in a classroom setting would be awesome!"

"I think more showcasing of work and collaboration is a good way for people to get to know each other so more of those."

\section{Discussion}

Although the response rate to the survey was low (18\%), the data do suggest that the specific diversity and inclusion activities we implemented in the computing classroom were in general a success (at least for the survey respondents and presumably for more of the class based on indirect verbal feedback to the instructor). The ice breakers and seat rotations helped students get to know one another and feel included in the classroom. The weekly computing contributors activity and to a slightly lesser extent the written computing contributor assignment did help students better appreciate diversity and the need for diversity in the field of computing. These activities were relatively easy to implement and only took 20 minutes (or 6\%) of class time each week.

The students offered some great suggestions for improvement including having even more opportunities for students to interact and get to know one another. Although students did sit in groups each week and were encouraged to interact with one another for lab assignments, because lab assignments had to be completed individually, many students chose to work on the assignments individually. Additional required group work (or even more showcasing of work as one student suggested) would foster more interaction. Also, it may be helpful to have students perform seat rotations every other week (instead of every week) - this would not allow them to meet every other student in the class, but would allow them to get to know a subset of students better.

The activities we used to expose students to role models from diverse background was effective for all but one student respondent. We attribute the success of these activities to the ability to tie the stories of the role models directly into the course material. This makes learning about the individuals feel part of the course, rather than just an afterthought to specifically promote diversity.

Although the activities described in this paper were specific to a computing classroom, they can be easily adapted to work in any classroom. It is our hope that this work inspires other educators to take small steps to embed diversity and inclusion into their everyday activities. 


\section{References}

[1] Forbes Technology Council. "12 Ways Diversity Makes a Difference in Tech." Forbes Magazine. July 12, 2018.

[2] Winning, Lisa. "It's Time To Prioritize Diversity Across Tech.” Forbes Magazine. March 13, 2018.

[3] Simmons, Denise R. and Lord, Susan. "Removing Invisible Barriers and Changing Mindsets to Improve and Diversify Pathways in Engineering." Advances in Engineering Education. 7(2). Spring 2019.

[4] Gunn, Dwyer. "These five tech companies are trying to solve Silicon Valley's diversity problem." The Guardian. June 6, 2016. https://www.theguardian.com/sustainable-business/2016/jun/06/siliconvalley-diversity-problem-tech-industry-solutions

[5] Romansky, Lauren and Strother, Emily. "Slack's Unique Diversity Strategy Offers Some Lessons for Silicon Valley and Beyond.” Talent Daily. May 15, 2018. Available:

https://www.cebglobal.com/talentdaily/slacks-unique-diversity-strategy-offers-some-lessons-forsilicon-valley-and-beyond/

[6] Broadening Participation in Computing. National Science Foundation's Directorate For Computer Information Science \& Engineering.

[7] INSIGHT Into Diversity Higher Education Excellence in Diversity (HEED) Award. 2019 Recipients. https://www.insightintodiversity.com/about-the-heed-award/2019-recipients/

[8] Saunders , Shari and Kardia, Diana. "Creating Inclusive College Classrooms." Center for Research on Learning and Teaching. University of Michigan. $1997 \mathrm{http} / / / w w w . c r l t . u m i c h . e d u / g s i s / p 3 \_1$

[9] McGuire, J. M. (2011). Inclusive College Teaching: Universal Design for Instruction and Diverse Learners. Journal of Accessibility and Design for All, 1(1), 38-54. https://doi.org/10.17411/jacces.v1i1.80

[10] Ruggs, Enrica \& Hebl, Michelle. Diversity, Inclusion, and Cultural Awareness for Classroom and Outreach Education. In B. Bogue \& E. Cady (Eds.). Apply Research to Practice (ARP) Resources. 2012.

[11] Allport, G. W. (1954). The nature of prejudice. Reading, MA: Addison Wesley

[12] Pettigrew, T. F., \& Tropp, L. R. (2006). A meta-analytic test of intergroup contact theory. Journal of Personality and Social Psychology, 90(5), 751-783

[13] Blanton, H., Crocker, J., \& Miller, D. T. (2000). The effects of in-group versus out-group social comparison on self-esteem in the context of a negative stereotype. Journal of Experimental Social Psychology, 36(5), 519-530.

[14] Marx, D. M., \& Roman, J. S. (2002). Female role models: Protecting women's math test performance. Personality and Social Psychology Bulletin, 28(9), 1183-1193

[15] Marx, D. M., Stapel, D. A., \& Muller, D. (2005). We can do it: The interplay of construal orientation and social comparison under threat. Journal of Personality and Social Psychology, 88(3), 432-446

[16] Cheryan, Sapna, Plaut, Victoria, Handrown, Caitlin, and Hudson, Lauren. "The Stereotypical Computer Scientist: Gendered Media Representations as a Barrier to Inclusion for Women." Sex Roles. July 2013, Volume 69, Issue 1-2. Pp 58-71

[17] Chlup DT, Collins TE: Breaking the ice: using ice-breakers and Re-energizers with adult learners. Adult Learn. 2010, 21: 3-4. 34-39

[18] Social golfer problem. https://demonstrations.wolfram.com/SocialGolferProblem/

[19] 100 Icebreaker Questions for College Students. https://www.signupgenius.com/college/icebreaker-questions-college-students.cfm 